\title{
In Vitro Comparison of Antifungal Activity between Epigallocatechin Gallate EGCG) and Nystatin on Candida Sp. Stored Isolates in HIV/AIDS Patients with Oral Candidiasis
}

\author{
Yusuf Wibisono $^{1}$, Afif Nurul Hidayati ${ }^{1}$, Sawitri $^{1}$, Cita Rosita Sigit Prakoeswa ${ }^{1}$, Iskandar \\ Zulkarnain ${ }^{1}$, Evy Ervianti ${ }^{1}$, Rahmadewi ${ }^{1}$, Esti Hendradi², Pepy Dwi Endraswari ${ }^{3}$, Dwi \\ Murtiastutik $^{1}$ \\ ${ }^{I}$ Department of Dermatology and Venereology, Faculty of Medicine, Universitas Airlangga/Dr. \\ Soetomo General Academic Hospital, Surabaya,Indonesia \\ ${ }^{2}$ Departement of Pharmaceutical Sciences, Faculty of Pharmacy, Universitas Airlangga, Surabaya, \\ Indonesia \\ ${ }^{3}$ Department of Microbiology, Faculty of Medicine, Universitas Airlangga/Dr. Soetomo General \\ Academic Hospital, Surabaya,Indonesia
}

\begin{abstract}
Background: Oral candidiasis is an oral infection caused by Candida albicans. It is one of the most common opportunistic infections found in patients with Human Immunodeficiency Virus (HIV)/Acquired Immune Deficiency Syndrome (AIDS). Due to growing resistance and side effects to common antifungal drugs in recent years, there have been many studies on natural substances as antifungal agents. In this study, Epigallocatechin gallate (EGCG) were examined for in vitro antifungal activity against Candida strains. Purpose: To compare the in vitro antifungal activity of EGCG and nystatin towards Candida sp. isolate in HIV/AIDS patients with oral candidiasis. Methods: This research was an experimental laboratory study conducted at the Dr. Soetomo General Academic Hospital, Surabaya. Forty isolates of Candida albicans and Candida non-albicans were included. The isolates were tested for antifungal activity using the well diffusion and microdilution method for nystatin 1000 IU and EGCG 1.25\%. Result: Diffusion test results showed a greater inhibition zone for nystatin against all analyzed Candida strains with an average diameter for Candida albicans formed by EGCG of $2.15 \mathrm{~mm}$ and $7.4 \mathrm{~mm}$ for Candida non-albicans. Meanwhile, based on the microdilution test, EGCG was better than nystatin towards all analyzed Candida strains. This study showed EGCG Minimum Fungicidal Concentration (MFC) as high as $50 \%(\mathrm{p}<0.05)$. Conclusion: Nystatin antifungal activity was better than EGCG supported by a greater inhibition zone in the well diffusion method. However, the antifungal activity of EGCG was better than nystatin based on microdilution methods.
\end{abstract}

Keywords: Antifungal, Candida, nystatin, Epigallocatechin gallate, AIDS/HIV

Correspondence: Dwi Murtiastutik, Department of Dermatology and Venereology Faculty of Medicine, Universitas Airlangga/Dr. Soetomo General Academic Hospital, Surabaya, Jl. Mayjen Prof. Dr. Moestopo No. 6-8 Surabaya 60131, Indonesia. Phone: (031) 5501609, e-mail: dwimurtiastutik@yahoo.co.id

\section{BACKGROUND}

Oral candidiasis is a fungal infection that affects the oral mucosa. This lesion is caused by the fungus Candida sp., an opportunistic fungal pathogen that should normally be in the gastrointestinal, genitourinary, oral, and conjunctival tracts. The most prevalent cause of candidiasis is Candida albicans, and it is also the primary cause of oral candidiasis because the species is mostly in the oral cavity. Oral candidiasis is also the most common opportunistic fungal infection in the oral cavity. In recent years, the pathogenic form of Candida sp. increased due to several factors, such as broad-spectrum antibiotics, immunosuppressive agents, transplants, catheters, and immunocompromised diseases, including diabetes, severe malnutrition, and Human Immunodeficiency
Virus (HIV). ${ }^{1,2,3}$

Patients with HIV develop immune system disorders (AIDS). According to WHO, oral candidiasis is one of the clinical manifestations in $45 \%$ to $90 \%$ of patients with HIV., ${ }^{4,5}$ The patient falls into an immunocompromised state. Patients become susceptible to various kinds of infections, either due to fungi, bacteria, or viruses. In 2017, the Ministry of Health of the Republic of Indonesia reported that oral candidiasis was the most common opportunistic infection in HIV patients $(80.8 \%){ }^{6}$ It can develop into systemic candidiasis with a mortality rate of up to $60 \%$. Immunocompromised patients have a higher mortality rate as their bodies are unable to eliminate $C$. albicans adhesions. ${ }^{7}$ In 2013, a retrospective study reported that 244 out of 301 HIV/AIDS patients with skin 
manifestations at the Infectious Disease Intermediate Care Unit Dr. Soetomo General Academic Hospital, patients had oral candidiasis. ${ }^{8}$

HIV patients require oral health checks as the manifestation of oral fungal infection is an early sign of HIV infection. It can predict the progression to AIDS related to the level of immunosuppression. Oral candidiasis is the most common manifestation of fungal infection in HIV/AIDS patients, and its incidence increases at higher stages of the disease. HIV patients tend to have lower antimicrobial peptides protective level such as histatin-5 (Hst-5) which make those patients more vulnerable to candida infection compared to healthy subjects. ${ }^{9}$ Furthermore, the management of candidiasis shall be based on the extent of infection. In limited Candida infection in the oral cavity, nystatin mouth rinse is a viable option for antifungal therapies. ${ }^{10}$

Meanwhile, in wider infections, it is necessary to provide an antifungal that works systemically. Currently, nystatin is the first-line antifungal drug used as a topical treatment option for oral candidiasis. ${ }^{1,10}$ There have been studies on antifungal resistance, especially nystatin, in both Candida albicans and Candida non-albicans. ${ }^{11-13}$

Research on alternative therapies using natural ingredients is currently on the rise. The use of natural extracts to treat Candida is becoming popular. Green tea (Camellia sinensis) extract is one of them, and it is found to have beneficial effects on health due to its low toxicity with antioxidant and immunomodulatory activity. In 2018, Rahayu and colleagues conducted a study on oral candidiasis involving mice with oral candidiasis. They took samples from the dorsal tongue with a swab and cultivated them on Sabouraud dextrose agar after Candidia albicans infection was confirmed by gram examination, and they used an active substance composition of $90 \%$ polyphenols and Epigallocatechin gallate (EGCG) as much as $25 \%$ and $50 \%$. The zone appeared in the experiment in 24 hours and 48 hours. The study reported that the minimum inhibitor concentration of green tea extract on the growth of Candida albicans was $12.5 \%$, and the minimum bactericidal concentration was $25 \%$. Madhura et al. also reported an antimycotic effect of the EGCG component by inhibiting biofilm formation and damaging the existing biofilm of Candida $s p .{ }^{14}$

Rahayu on the immunomodulatory effects of green tea leaf extract in immunocompromised rats with Candida albicans infection evaluated the effect of green tea leaf extract (EGCG) at a concentration of $1.25 \%, 7$ days of administration. After evaluation, it was found that EGCG $1.25 \%$ had an immunomodulating effect against $C$. albicans infection in immunocompromised mice by the increased expression of IL-8, IL-17A, and HBD-2. Administering EGCG can provide an immunomodulating effect against oral candidiasis in immunocompromised patients. ${ }^{7}$ Therefore, this study aimed to evaluate the sensitivity of green tea extract (EGCG) and nystatin in oral candidiasis HIV patients. EGCG was expected to have better sensitivity than nystatin. This study was expected to provide practical contributions to the development of oral candidiasis herbal medicine for HIV/AIDS patients.

\section{METHODS}

This was an experimental laboratory study with a posttest-only design conducted at the Outpatient and Inpatient Units of the Infectious Disease Intermediate Care Unit (UPIPI), Dr. Soetomo General Academic Hospital, Surabaya from December 2019 to January 2020. Twenty isolates of Candida albicans and 20 isolates of Candida non-albicans were obtained from forty HIV/AIDS patients with OC using the swab method to the lesional sites. We used an over the counter topical nystatin 1000 IU and EGCG 1.25\% suspension made from Camelia sinensis extract powder (Sigma Aldrich, USA). We used the well diffusion method to determine the inhibition zone and the microdilution method to determine the minimum inhibitory concentration (MIC) and minimum fungicidal concentration (MFC) in the culture of 96well cell plates. Row 1 had the highest drug concentration and the lowest concentration at row 10 . The microtiter plates were incubated at $37^{\circ} \mathrm{C}$ for 24 to 48 hours. The MIC was determined by observing at which concentration the solution in the well begins to clear, and no deposits observed, indicating inhibited Candida. The MFC was tested by taking $10 \mu \mathrm{L}$ from the well with the MIC determined by each inoculated well. The MIC end-point was observed and interpreted as per the clinical and laboratory standard nstitute (CLSI) guidelines. The MFC means the lowest concentration without growth, serving as the end-point for the fungicidal effect. The MIC means the lowest concentration for at least $80 \%$ inhibition of microbial growth, initially identified by the visual method. The results were analyzed using SPSS 21. The statistical significance was determined at $\mathrm{p} \leq 0.05$ (CI 95\%). This research has been reviewed and approved by the Ethics Committee at the Dr. Soetomo General Academic Hospital.

\section{RESULT}

The inhibition zone obtained from antifungal sensitivity assessment using the well diffusion method showed that nystatin worked superiorly towards EGCG 
by forming wider inhibition zones in all Candida strains.

Table 1 shows the inhibition zone formed by EGCG $1.25 \%$ was smaller than the one formed by nystatin for all Candida strains. The mean values of the inhibition zone formed against Candida albicans by nystatin were $5.25 \mathrm{~mm}$ and $2.15 \mathrm{~mm}$ by EGCG. The mean value of the inhibition zone formed against Candida non-albicans by nystatin was $13.65 \mathrm{~mm}$, while the mean value of the inhibition zone formed by EGCG was $7.4 \mathrm{~mm}$. Nystatin performed better than EGCG based on the sensitivity test using the well method. Statistically, the p-value obtained from this study was $\mathrm{p}<0.001$, with a significant difference between the inhibition zones formed by nystatin and EGCG.

This study showed that with the microdilution method, the MFC of nystatin was obtained above $100 \%$. Statistically, the MFC produced by EGCG on Candida albicans showed a significant difference in the microdilution results at a concentration of $100 \%$ to $50 \%$ between nystatin and EGCG $(\mathrm{p}<0.005)$. At a concentration of $25 \%$, there was no significant difference $(p>0.005)$, and at a concentration of $12.5 \%$ to $0.19 \%$, it could not be analyzed because the results were visibly turbid. Therefore, it can be concluded that EGCG had better sensitivity than nystatin as an antifungal in Candida albicans.

The chi-square test results on Candida nonalbicans showed a significant difference in the microdilution results of $100 \%$ to $50 \%$ concentrations between nystatin and EGCG $(\mathrm{p}<0.005)$. In microdilution at concentrations of $25 \%$ to $0.19 \%$, it could not be analyzed because fungal growth was still present. With the microdilution method, the MFC of nystatin against Candida non-albicans was $100 \%$. Therefore, it can be concluded that EGCG had better sensitivity than nystatin as an antifungal in Candida albicans.

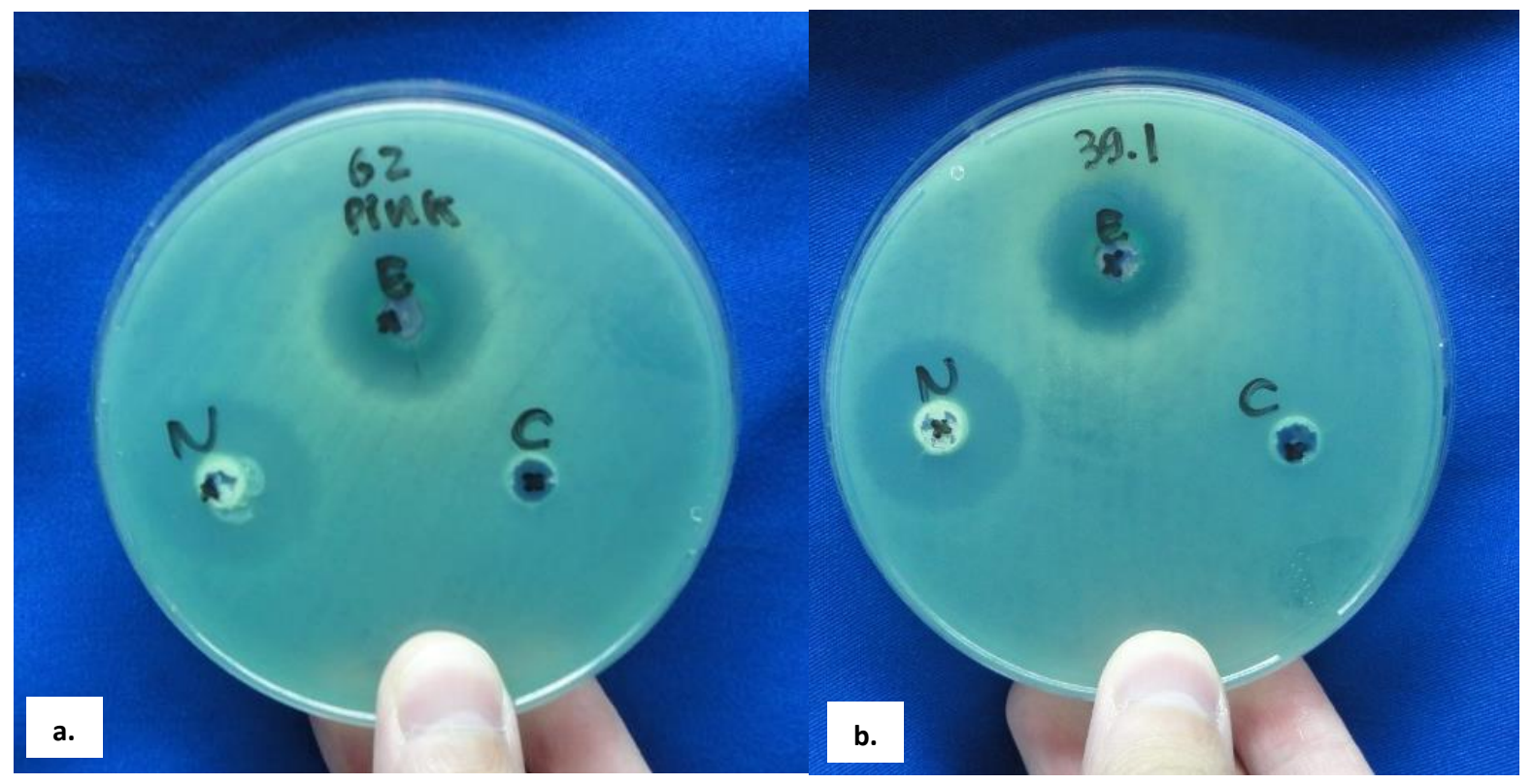

Figure 1. Diffusion test for nystatin and Epigallocatechin gallate (EGCG) antifungal activity. a. Inhibition zone made by nystatin and EGCG for Candida albicans. This picture showed that the inhibition zone formed by nystatin was $25 \mathrm{~mm}$, while EGCG was $20 \mathrm{~mm}$. b. Inhibition zone made by nystatin and EGCG for Candida non-albicans. This picture showed that the inhibition zone formed by nystatin was $24 \mathrm{~mm}$, while EGCG was 20 mm. (N: Nystatin; E: EGCG; C: Control)

Table 1. Growth Inhibition Zones of $1.25 \%$ Epigallocatechin gallate (EGCG) and nystatin against Candida sp.

\begin{tabular}{cllcc}
\hline Species & Treatment & $\mathrm{n}$ & $\begin{array}{c}\text { Mean }(\min -\mathrm{max}) \\
\text { Inhibition zone }(\mathrm{mm})\end{array}$ & $\mathrm{P}$ \\
\hline \multirow{2}{*}{ Candida albicans } & Nystatin & 20 & $5.25(0-35)$ & $<0.001$ \\
& EGCG & 20 & $2.15(0-37)$ & $<0.001$ \\
\hline \multirow{2}{*}{ Candida non-albicans } & Nystatin & 20 & $13.65(0-37)$ & $7.4(0-25)$ \\
\hline
\end{tabular}


Table 2. The Minimum Inhibitory Concentration (MIC) values of 1.25\% Epigallocatechin gallate (EGCG) and Nystatin against Candida albicans

Concentration $(\%)$

Treatment

$\mathrm{P}$

\begin{tabular}{|c|c|c|c|c|}
\hline & & Nystatin & EGCG & \\
\hline \multirow{2}{*}{ Microdilution 100} & $(+)$ & $20(100 \%)$ & $0(0 \%)$ & \multirow{2}{*}{$<0.001$} \\
\hline & $(-)$ & $0(0 \%)$ & $20(100 \%)$ & \\
\hline \multirow{2}{*}{ Microdilution 50} & $(+)$ & $20(100 \%)$ & $0(0 \%)$ & \multirow{2}{*}{$<0.001$} \\
\hline & $(-)$ & $0(0 \%)$ & $20(100 \%)$ & \\
\hline \multirow{2}{*}{ Microdilution 25} & $(+)$ & $20(100 \%)$ & $19(95 \%)$ & \multirow{2}{*}{1.000} \\
\hline & $(-)$ & $0(0 \%)$ & $1(5 \%)$ & \\
\hline \multirow{2}{*}{ Microdilution 12.5} & $(+)$ & $20(100 \%)$ & $20(100 \%)$ & \multirow{2}{*}{ - } \\
\hline & $(-)$ & $0(0 \%)$ & $0(0 \%)$ & \\
\hline \multirow{2}{*}{ Microdilution 6.25} & $(+)$ & $20(100 \%)$ & $20(100 \%)$ & \multirow{2}{*}{ - } \\
\hline & $(-)$ & $0(0 \%)$ & $0(0 \%)$ & \\
\hline \multirow{2}{*}{ Microdilution 3.125} & $(+)$ & $20(100 \%)$ & $20(100 \%)$ & \multirow[b]{2}{*}{-} \\
\hline & $(-)$ & $0(0 \%)$ & $0(0 \%)$ & \\
\hline \multirow{2}{*}{ Microdilution 1.56} & $(+)$ & $20(100 \%)$ & $20(100 \%)$ & \multirow[b]{2}{*}{-} \\
\hline & $(-)$ & $0(0 \%)$ & $0(0 \%)$ & \\
\hline \multirow{2}{*}{ Microdilution 0.78} & $(+)$ & $20(100 \%)$ & $20(100 \%)$ & \multirow[b]{2}{*}{ - } \\
\hline & $(-)$ & $0(0 \%)$ & $0(0 \%)$ & \\
\hline \multirow{2}{*}{ Microdilution 0.38} & $(+)$ & $20(100 \%)$ & $20(100 \%)$ & \multirow{2}{*}{-} \\
\hline & $(-)$ & $0(0 \%)$ & $0(0 \%)$ & \\
\hline \multirow{2}{*}{ Microdilution 0.19} & $(+)$ & $20(100 \%)$ & $20(100 \%)$ & \multirow{2}{*}{ - } \\
\hline & $(-)$ & $0(0 \%)$ & $0(0 \%)$ & \\
\hline
\end{tabular}

Note: $(+)=$ growth; (-) no growth

Table 3. The Minimum Inhibitory Concentration (MIC) values of 1.25\% Epigallocatechin gallate (EGCG) and Nystatin against Candida non-albicans

Concentration (\%) $\quad$ Treatment $\quad \mathrm{P}$

\begin{tabular}{|c|c|c|c|c|}
\hline & & Nysta & & \\
\hline \multirow{2}{*}{ Microdilution 100} & $(+)$ & $20(100 \%)$ & $0(0 \%)$ & \multirow{2}{*}{$<0.001$} \\
\hline & $(-)$ & $0(0 \%)$ & $20(100 \%)$ & \\
\hline \multirow{2}{*}{ Microdilution 50} & $(+)$ & $20(100 \%)$ & $0(0 \%)$ & \multirow{2}{*}{$<0.001$} \\
\hline & $(-)$ & $0(0 \%)$ & $20(100 \%)$ & \\
\hline \multirow{2}{*}{ Microdilution 25} & $(+)$ & $20(100 \%)$ & $20(100 \%)$ & \multirow{2}{*}{-} \\
\hline & $(-)$ & $0(0 \%)$ & $0(0 \%)$ & \\
\hline \multirow{2}{*}{ Microdilution 12.5} & $(+)$ & $20(100 \%)$ & $20(100 \%)$ & \multirow{2}{*}{-} \\
\hline & $(-)$ & $0(0 \%)$ & $0(0 \%)$ & \\
\hline \multirow{2}{*}{ Microdilution 6.25} & $(+)$ & $20(100 \%)$ & $20(100 \%)$ & \multirow{2}{*}{ - } \\
\hline & $(-)$ & $0(0 \%)$ & $0(0 \%)$ & \\
\hline \multirow{2}{*}{ Microdilution 3.125} & $(+)$ & $20(100 \%)$ & $20(100 \%)$ & \multirow{2}{*}{-} \\
\hline & $(-)$ & $0(0 \%)$ & $0(0 \%)$ & \\
\hline \multirow{2}{*}{ Microdilution 1.56} & $(+)$ & $20(100 \%)$ & $20(100 \%)$ & \multirow{2}{*}{ - } \\
\hline & $(-)$ & $0(0 \%)$ & $0(0 \%)$ & \\
\hline \multirow{2}{*}{ Microdilution 0.78} & $(+)$ & $20(100 \%)$ & $20(100 \%)$ & \multirow{2}{*}{-} \\
\hline & $(-)$ & $0(0 \%)$ & $0(0 \%)$ & \\
\hline \multirow{2}{*}{ Microdilution 0.38} & $(+)$ & $20(100 \%)$ & $20(100 \%)$ & \multirow[b]{2}{*}{ - } \\
\hline & $(-)$ & $0(0 \%)$ & $0(0 \%)$ & \\
\hline \multirow{2}{*}{ Microdilution 0.19} & $(+)$ & $20(100 \%)$ & $20(100 \%)$ & \multirow{2}{*}{ - } \\
\hline & $(-)$ & $0(0 \%)$ & $0(0 \%)$ & \\
\hline
\end{tabular}

Note: $(+)=$ growth; $(-)$ no growth 
Table 4. Minimum Fungicida Concentration (MFC) value of Epigallocatechin gallate (EGCG) on the growth of Candida albicans and Candida non-albicans.

\begin{tabular}{lccc}
\hline \multicolumn{1}{c}{ Species } & $\mathrm{n}$ & Mean (min-max) MFC & $\mathrm{P}$ \\
\hline Candida albicans & 20 & $2.05(2-3)$ & 0.672 \\
Candida non-albicans & 20 & $1.95(0-3)$ & \\
\hline
\end{tabular}

The normal distribution test of MFC data in each species of the EGCG group using the Shapiro-Wilk test showed that the data were not normally distributed ( $p$ $<0.005)$. The MFC differences between Candida albicans and Candida non-albicans were analyzed using the Mann Whitney test, and the results showed no significant difference in MFC between Candida albicans and Candida non-albicans ( $\mathrm{p}>0.005)$.

\section{DISCUSSION}

The average inhibition zone formed by Candida albicans was $5.35 \mathrm{~mm}$, and the inhibition zone formed by EGCG was smaller at $2.15 \mathrm{~mm}$. We used the Mann Whitney to determine whether there was a difference in the diameter of the growth inhibition zone of Candida albicans and Candida non-albicans at $50 \mathrm{~g} /$ disk nystatin and $1.25 \%$ EGCG. Statistically, the $\mathrm{p}$-value obtained from this study is $\mathrm{p}<0.001$, where there is a significant difference between the inhibition zone formed by nystatin and the zone formed by EGCG. The results showed that the EGCG inhibition zone, compared with nystatin p-value in the well method test, was still smaller so that the antifungal activity of nystatin was better than EGCG the well method.

A study examining the susceptibility of $C$. albicans to EGCG as a single agent and in combination with an antifungal agent by the microdilution method showed that EGCG has pH-dependent anti-C. The combination of EGCG and an antifungal agent (amphotericin B, fluconazole) inhibits the growth of different reference strains showing a synergistic effect. Results from another investigation evaluating the antifungal activity of EGCG in 21 clinical isolates from seven Candida sp. in vitro showed most promising results. EGCG can be used as an agent or adjuvant for antifungal therapy in oral candidiasis ${ }^{15,16}$.

The data were not normally distributed ( $p>$ 0.005) that we used the Mann Whitney test. The inhibition zone of EGCG for Candida non-albicans was smaller than the nystatin. The mean value of the inhibition zone formed by nystatin was $13.65 \mathrm{~mm}$, and the mean value of the inhibition zone formed by EGCG was $7.4 \mathrm{~mm}$. The study's statistical value was $p$-value $<0.001$, and there was a significant difference between the inhibition zone formed by nystatin and EGCG.

The Candida non-albicans inhibition zone of EGCG was a half smaller than nystatin, greater than that of Candida sp., which is $1 / 3$ nystatin. Previous studies also showed the inhibition zones in C. glabrata, C. guilliemondii, and C. parapsilosis showed the highest susceptibility. The $C$. glabrata were the most commonly found Candida non-albicans strains in HIV-infected patients and were highly susceptible to EGCG, even at low doses, although they were less effective than nystatin. These results indicated the potential of EGCG as an antifungal or adjuvant agent in oral candidiasis with minimum side effects ${ }^{16,17}$.

The MFC of nystatin could not be determined because it was visibly turbid, even at $100 \%$ concentration. Statistically, the MFC of EGCG in Candida albicans showed a significant difference in microdilution results at concentrations of $100 \%$ to $50 \%$ between nystatin and EGCG $(\mathrm{p}<0.005)$. Furthermore, at a concentration of $25 \%$, there was no significant difference $(p>0.005)$, and at a concentration of $12.5 \%$ to $0.19 \%$, it could not be analyzed because it was visibly turbid.

Previous studies on the inhibitory mechanism of EGCG reported a high MFC against $C$. albicans. The inhibitory effect of EGCG on $C$. albicans via key enzymes in the biosynthesis of purines, pyrimidines, and some amino acids, is independent to $\mathrm{pH}$. When EGCG is combined with azole antifungals (ketoconazole and itraconazole) or inhibitors of the ergosterol biosynthetic pathway, the main effect is synergistic. $^{18}$

This study also looked at the MFC of EGCG and nystatin against Candida non-albicans and reported the same results for Candida albicans. The MFCs of EGCG in Candida non-albicans were found at concentrations of $100 \%$ and $50 \%$ that all Candida albicans isolates had no turbidity. It means that, at these concentrations, the fungal growth could be inhibited.

In previous studies, the growth of Candida $s p$. was evaluated in EGCG alone or combination with azole drugs. The MIC and sub-MIC values showed a significant inhibitory effect on the growth of $C$. albicans, C.dubliniensis, C. glabrata, and a synergistic combination of EGCG and fluconazole and ketoconazole. EGCG and fluconazole or ketoconazole showed a synergistic effect, leading to the inhibition of fungicidal activity. The result of EGCG (MFC) alone in 4 species showed a $95.13 \%$ reduction, while in synergistic combination, the result showed $92.27 \%$ and $97.51 \%$ reduction, compared to controls. ${ }^{19}$ 
The Shapiro-Wilk test result on MFC data of EGCG showed that the data were not normally distributed $(\mathrm{p}<0.005)$. Therefore, the MFC differences between Candida albicans and Candida non-albicans were analyzed using the Mann Whitney test. The results of the Mann Whitney test showed no significant difference in MFC between Candida albicans and Candida non-albicans $(\mathrm{p}>0.005)$.

In in-vitro studies, it was shown that EGCG, Epigallocatechin (EGC), and Epicatechin gallate (ECG) caused metabolic instability of $C$. albicans cultures, even at the physiological polyphenol concentrations found in green tea. Of the three catechins, EGCG was the strongest in slowing down the formation and maintenance of Candida biofilms and interfering with biofilms formation. It was shown that higher EGCG concentrations inhibited the chymotrypsin-like activity of $C$. albicans in-vivo, which suggests that the impaired proteasomal activity contributes to the metabolic and cellular structural disorders of this fungus. ${ }^{18}$

Our study found an incongruity between the well diffusion and microdilution methods results. This might be due to the inability of EGCG suspension, like any other natural substance, to perform an optimum antifungal potency through the diffusion method. This method was not sufficiently sensitive for some extracts. The diffusion assay is limited to substances with considerable water solubility. Growth media and compound doses employed in this test system varied much and hampered the interpretation of results. However, the method is still routinely used in clinical practice due to its simplicity, quick and low cost to evaluate drug susceptibility, and it was settled for licensed drugs. Thus, this method is the first choice for licensed drugs but might not perform well on natural substances. ${ }^{20-22}$

On the other hand, the microdilution test was more sensitive and able to provide quantitative results, making this method more objective. Performing this method, we were able to detect the MIC, which is important for researching and producing new antifungal drugs. However, this method took a longer time to perform compared to the diffusion method and should be done by an expert to avoid misstep and misinterpretation.

Further research on EGCG antifungal activity is needed, especially in the active substance concentration and its optimum potency. Combining the available licensed drug can also be evaluated to provide better therapeutic results, especially in oral candidiasis cases.

\section{REFERENCES}

1. Marak MB, Dhanashree B. Antifungal susceptibility and biofilm production of Candida spp. isolated from clinical samples. Int $\mathrm{J}$ Microbiol 2018; 2018(1): 1-5.

2. Nur'aeny N, Hidayat W, Dewi TS, Herawati E, Wahyuni IS. Profil oral candidiasis di bagian ilmu penyakit mulut RSHS Bandung periode 20102014. Majalah Kedokteran Gigi Indonesia 2014; 3(1) :23-8.

3. Patil S, Majumdar B, Sarode SC, Sarode GS, Awan KH. Oropharyngeal candidosis in HIVinfected patients-an update. Front Microbiol 2018; 9(1): 1-9.

4. Cuesta CG, Perez MGS, Bagan JV. Current treatment of oral candidiasis: a literature review. J Clin Exp Dent 2014; 6(5): 576-82.

5. Warrier SA, Sathasivasubramanian S. Human immunodeficiency virus induced oral candidiasis. J Pharmacy Bioallied Sci 2015; 7(2): 812-4.

6. Dewi ISL, Hidayati AN. Manifestasi kelainan kulit pada pasien HIV \& AIDS. Berkala Ilmu Kesehatan Kulit dan Kelamin 2015; 27(2): 97105.

7. Putranti, A. Oral candidiasis as clinical manifestation of HIV/AIDS infection in Airlangga University hospital patients. IOP Conf. Ser Earth Environ Sc 2018; 125(1): 120-63.

8. Rahayu RP, Prasetyo RA, Purwanto DA, Kresnoadi U, Iskandar RPD, Rubianto M. The immunomodulatory effect of green tea (camellia sinensis) leaves extract on immunocompromised wistar rats infected candida albicans. Vet World 2018; 11(5): 765-70.

9. Vila T, Sultan AS, Montelongo-Jauregui D, Jabra-Rizk MA. Oral Candidiasis: A Disease of Opportunity. J Fungi 2020; 6(1): 15

10. Suyoso S, Ervianti E, Barakbah J. Kandidiasis mukosa. In: Suyoso S, Ervianti E, Barakbah J, editors. Panduan Praktik Klinis SMF Ilmu Kesehatan Kulit dan Kelamin RSUD Dr. Soetomo. Surabaya: RSUD Dr. Soetomo; 2014. p.95-7.

11. Khalandi H, Masoori L, Farahyar S, Delbandi AA, Raiesi O, Farzanegan A, et al. Antifungal activity of capric acid, nystatin, and fluconazole and their in vitro interactions against candida isolates from neonatal oral thrush. Assay Drug Dev. Technol 2020; 18(3): 1-7.

12. Moges B, Bitew A, Shewaamare A. Spectrum and the in vitro antifungal susceptibility pattern of yeast isolates in ethiopian HIV patients with 
oropharyngeal candidiasis. Int $\mathrm{J}$ Microbiol 2016;2016(1): 1-8.

13. Yassin MT, Mostafa AA, Al-Askar AA, Bdeer R. In vitro antifungal resistance profile of candida strains isolated from Saudi women suffering from vulvovaginitis. Eur J Pharm Med Res 2020; 25(1): 1-9.

14. Madhura MG, Shweta RD, Kumar BV, Savithri D, Gajalakshmi S, Soumya BV. Antifungal effect of green tea extracts on oral candida species: an in vitro study. J. adv. clin. res. insight 2016;3(1): 1-4.

15. Matsumoto Y, Kaihatsu K, Nishino K, Ogawa M, Kato N, Yamaguchi A. Antibacterial and antifungal activities of new acylated derivatives of epigallocatechin gallate. Front Microbiol 2012; 3(1): 53-5.

16. Steinmann J, Buer J, Pietschmann T, Steinmann E. Anti-infective properties of epigallocatechin3-gallate (EGCG), a component of green tea. Br J Pharmacol 2013; 168(5): 1059-73.

17. Spalanzani RN, Mattos K, Marques LI, Barros PFD, Pereira PIP, Paniago AMM, et al. Clinical and laboratorial features of oral candidiasis in
HIV-positive patients. Rev Soc Bras Med Trop 2018; 51(3): 352-6

18. Granja A, Frias I, Neves I, Neves AR, Pinheiro M, Reis S. Therapeutic potential of epigallocatechin gallate nanodelivery systems. Hindawi BioMed Res Int 2017; 2017(1): 1-15.

19. Behbehani JM, Irshad M, Shreaz S, Karched, M. Synergistic effects of tea polyphenol epigallocatechin 3-O-gallate and azole drugs against oral candida isolates. J Mycol Méd 2019; 29(2): 158-67.

20. Scorzoni L, Benaducci T, Almeida AMF, Silva DHS, Bolzani VS, Gianinni MJSM. The use of standard methodology for determination of antifungal activity of natural products against medical yeasts candida $\mathrm{sp}$ and cryptococcus $\mathrm{sp}$. Brazilian J Microbiol 2007; 38(1): 391-7.

21. Balouiri M, Sadiki M, Ibnsouda SK. Methods for in vitro evaluating antimicrobial activity: A review. J Pharm Anal 2016; 6(2): 71-9.

22. Khan ZA, Siddiqui ME, Park S. Current and Emerging Methods of Antibiotic Susceptibility Testing. Diagnostics 2019; 9(2): 49 